\title{
Resilience of caregivers of people with dementia: a systematic review of biological and psychosocial determinants
}

\author{
Resiliência de cuidadores de pessoas com demência: revisão sistemática de \\ determinantes biológicos e psicossociais
}

Rachel Dias, Raquel Luiza Santos, Maria Fernanda Barroso de Sousa, Marcela Moreira Lima Nogueira, Bianca Torres, Tatiana Belfort, Marcia Cristina Nascimento Dourado

\begin{abstract}
Introduction: Although caregivers of people with dementia may face difficulties, some positive feelings of caregiving may be associated with resilience.

Objective: This study systematically reviewed the definitions, methodological approaches and determinant models associated with resilience among caregivers of people with dementia.

Methods: Search for articles published between 2003 and 2014 in ISI, PubMed/MEDLINE, SciELO and Lilacs using the search terms resilience, caregivers and dementia.

Results and conclusions: Resilience has been defined as positive adaptation to face adversity, flexibility, psychological well-being, strength, healthy life, burden, social network and satisfaction with social support. No consensus was found about the definition of resilience associated with dementia. We classified the determinant variables into biological, psychological and social models. Higher levels of resilience were associated with lower depression rates and greater physical health. Other biological factors associated with higher levels of resilience were older age, African-American ethnicity and female sex. Lower burden, stress, neuroticism and perceived control were the main psychological factors associated with resilience. Social support was a moderating factor of resilience, and different types of support seemed to relieve the physical and mental overload caused by stress.
\end{abstract}

Keywords: Psychological resilience, caregiver, dementia, depression.

\section{Resumo}

Introdução: Apesar das dificuldades enfrentadas por cuidadores de pessoas com demência, sentimentos positivos quanto aos cuidados podem estar relacionados à resiliência.

Objetivo: Revisamos sistematicamente a literatura sobre a conceituação, abordagens metodológicas e modelos determinantes relacionados à resiliência dos cuidadores de pessoas com demência. Métodos: Foi realizada uma busca por artigos publicados entre 2003 e 2014 nas bases de dados ISI, PubMed/MEDLINE, SciELO e Lilacs, usando os descritores resilience [resiliência], caregivers [cuidadores] e dementia [demência].

Resultados e conclusões: A resiliência foi definida como adaptação positiva para enfrentar adversidades, flexibilidade, bem-estar psicológico, força, vida saudável, sobrecarga, rede social e satisfação com o apoio social recebido. Não se encontrou consenso sobre o conceito de resiliência em relação à demência. As variáveis determinantes foram classificadas em modelos biológicos, psicológicos e sociais. Níveis mais altos de resiliência foram relacionados com taxas mais baixas de depressão e melhor saúde física. Os outros aspectos biológicos relacionados a níveis mais altos de resiliência foram idade avançada, etnia de origem africana e sexo feminino. Menos sobrecarga, estresse, neuroticismo e percepção de controle foram os principais aspectos psicológicos relacionados à resiliência. $\mathrm{O}$ apoio social foi um fator moderador da resiliência, pois uma variedade de tipos de apoio parece aliviar a sobrecarga física e mental causada pelo estresse. Descritores: Resiliência psicológica, cuidador, demência, depressão.

Center for Alzheimer's Disease and Related Disorders, Institute of Psychiatry, Universidade Federal do Rio de Janeiro (UFRJ), Rio de Janeiro, RJ, Brazil. Financial support: Fundação de Amparo à Pesquisa do Estado do Rio de Janeiro (grant no. E-26/102.256/2010).

Submitted Jul 21 2014, accepted for publication Sep 10 2014. No conflicts of interest declared concerning the publication of this article.

Suggested citation: Dias R, Santos RL, de Sousa MF, Nogueira MM, Torres B, Belfort T, et al. Resilience of caregivers of people with dementia: a systematic review of biological and psychosocial determinants. Trends Psychiatry Psychother. 2014;37(1):12-19. http://dx.doi.org/10.1590/2237-6089-2014-0032. Epub Jan 30, 2015. 


\section{Introduction}

Dementia leads to progressive and irreversible cognitive and functional impairment, and people with dementia become dependent on caregivers, generally family members. ${ }^{1-4}$ The negative health consequences of looking after an older family member with dementia, particularly the effects on mental and physical health, are well documented. ${ }^{5-12}$ People with dementia often have an array of neuropsychiatric symptoms, such as mood disorders, delusions, hallucinations, vegetative symptoms and psychomotor abnormalities. Neuropsychiatric symptoms are the most important factors in caregiver burden. 7,13

Although caregivers of people with dementia face many difficulties, they may also experience positive emotional responses, ${ }^{12,14}$ which may be associated with resilience $^{3}$ and, consequently, with positive feelings about caring. ${ }^{12}$

Resilience may be defined as a dynamic process involving the interaction between both risk and protective factors, internal and external to the individual, that act to modify the effects of an adverse life event. ${ }^{15,16}$ It is a process related to adaptive capacities or to a positive trajectory of functioning and adaptation after a traumatic situation. . $2,4,5,13,14,17,18^{-1}$

Resilience is not invulnerability to stress, but, rather, the ability to recover from negative events. ${ }^{19}$ It corresponds to a transactional process mediated by the interaction between the individual and the environment. Therefore, risk and protective factors, typically associated with patterns of negative and positive adaptation in the face of risk, are important aspects of resilience. Both risk and protective factors have relevant elements in various domains of human functioning, such as personal attributes, family structure and dynamics, social context, cultural aspects and specific events. ${ }^{20}$ Trombeta \& Guzzo ${ }^{21}$ suggested that resilience is a balanced scale between a stressful event, threats, suffering and adverse conditions. These reveal vulnerability and strengths, skills, capacity of reaction and coping, some of the characteristics of resilient individuals.

Resilience, satisfaction with caregiving, coping, social support and a strong sense of spirituality have been posited as protective factors that mediate negative health outcomes. ${ }^{18,22-24}$ Other mediating mechanisms are coping strategies and a sense of coherence..$^{8,12,19}$ Coping strategies are a dynamic set of cognitive and behavioral efforts to cope with internal and external demands perceived as burdens when compared with personal resources. ${ }^{20}$ In contrast, the sense of coherence depends on the ability to realize that the situation is understandable or predictable and to perceive one's ability to cope in a difficult situation and to find meaning in everyday events or problems faced. ${ }^{25}$

Resilience helps caregivers maintain their mental and physical stability, fostering caregiving and providing better health and quality of life for the care recipient. ${ }^{3}$ Therefore, resilience is a complex construct, as it involves the interaction between adverse life events and internal and external individual factors. 2,26 However, differences in the definition of resilience result in the use of diverse methodological approaches.

This systematic review compared the definitions, methodological approaches and determinant models of resilience among caregivers of people with dementia. It also investigated how resilience is defined in the field of dementia and which factors significantly determine low and high levels of resilience among caregivers of people with dementia.

\section{Method}

A literature search was conducted using the Web of Knowledge Cross Search (Thomson Scientific/ISI Web Services), MEDLINE (PubMed) and SciELO databases to select studies about resilience of caregivers of people with dementia published in Portuguese, English or Spanish from January 2003 to June 2014. The search terms were resilience, caregivers and dementia, in the following combination: resilience AND caregivers AND dementia.

Inclusion criteria were: studies about resilience of caregivers of people with the dementia; crosssectional or longitudinal; randomized or nonrandomized, controlled or not controlled.

We excluded studies about: resilience of caregivers of elderly people not diagnosed with dementia; resilience of people with dementia or mourning; caregivers of people with other pathologies; assessment and validation of instruments for caregivers or patients; euthanasia; efficacy of non-pharmacological interventions not designed to investigate resilience; effect of caregiver attachment on patient care; healthy aging and systematic reviews; and articles with no patient samples.

Two independent reviewers read the abstracts and included studies according to their contents. In case of disagreement, a third reviewer made the decision after reading the title and abstract. After that, full manuscripts were read to check inclusion and exclusion criteria. We used a standardized form, according to the recommendations of the Cochrane Collaboration. ${ }^{27}$ 


\section{Sample}

We found 56 articles: 25 in the Web of Knowledge Cross Search, 30 in PubMed/MEDLINE and one in SciELO. After the exclusion of redundant crossreferences $(n=11), 45$ studies were selected. Thirtyone studies were excluded for different reasons, as shown in Table 1. We added one study manually, and our sample comprised the complete texts of 15 studies.

\section{Results}

In the studies reviewed, resilience was defined as positive adjustment in case of adversity, ${ }^{1,2,4,5,13,14,18}$ beliefs about one's own abilities and internal locus of control, ${ }^{6}$ psychological well-being and strength, ${ }^{12}$ coping development of healthy life, ${ }^{3}$ perceived burden ${ }^{28}$ and network size or satisfaction with social support. ${ }^{29}$ Only two studies did not define resilience. ${ }^{7,24}$

Table 1 - Studies excluded according to criterion

\begin{tabular}{|c|c|c|}
\hline Domains & Exclusion criteria & Excluded \\
\hline \multirow[t]{12}{*}{ Participants } & $\mathbf{n}=\mathbf{3 1}$ & \\
\hline & $\downarrow$ & \\
\hline & Other pathologies & 03 \\
\hline & Healthy aging & 01 \\
\hline & Children that live with people with dementia & 01 \\
\hline & Caregivers of elderly with or without dementia that live in an institution & 03 \\
\hline & Resilience of people with dementia & 01 \\
\hline & Euthanasia of people with severe dementia & 01 \\
\hline & Older veteran caregivers & 01 \\
\hline & Caregivers of healthy elderly & 02 \\
\hline & $\downarrow$ & \\
\hline & $\mathbf{n}=\mathbf{1 8}$ & \\
\hline \multirow[t]{4}{*}{ Study design } & Review & 03 \\
\hline & Conference & 01 \\
\hline & $\downarrow$ & \\
\hline & $n=14$ & \\
\hline \multirow[t]{3}{*}{ Interventions } & Non-pharmacological & 03 \\
\hline & $\downarrow$ & \\
\hline & $\mathbf{n}=\mathbf{1 1}$ & \\
\hline \multirow[t]{4}{*}{ Assessment } & Validation of instruments & 02 \\
\hline & Salivary cortisol & 02 \\
\hline & $\downarrow$ & \\
\hline & $\mathbf{n}=\mathbf{7}$ & \\
\hline \multirow{6}{*}{$\begin{array}{l}\text { Other factors that affect caregivers and } \\
\text { people with dementia }\end{array}$} & Mourning & 01 \\
\hline & Implication on caregiving & 02 \\
\hline & Effects of bonds & 01 \\
\hline & Job satisfaction and career commitment & 01 \\
\hline & $\downarrow$ & \\
\hline & $\mathbf{n}=\mathbf{2}$ & \\
\hline \multirow[t]{3}{*}{ Only abstract } & Resilience and suicide & 02 \\
\hline & $\downarrow$ & \\
\hline & $\mathbf{n}=\mathbf{0}$ & \\
\hline
\end{tabular}


Studies were classified into three areas according to determinant factors, as described below.

\section{Resilience and psychological factors ( $n=15)$}

Higher levels of resilience were associated with psychological factors, such as coping strategies, ${ }^{10,12}$ positive cognitions, ${ }^{1}$ resources, ${ }^{1}$ optimism, ${ }^{6}$ self-efficacy, ${ }^{6}$ internal locus of control, ${ }^{6}$ full engagement in daily activities $^{4}$ and search for challenges. ${ }^{4}$ Higher levels of resilience were also associated with decreased burden, 1,2,28 stress, ${ }^{6}$ neuroticism, ${ }^{2}$ perceived control $^{4}$ and distress. ${ }^{5,24}$ A study found that caregivers that provided care for a longer duration of time had higher levels of resilience. ${ }^{28}$ Another study showed that resilience did not significantly explain caregiver's sense of marital satisfaction. ${ }^{13}$

\section{Resilience and biological factors ( $\mathrm{n}=9$ )}

Higher levels of resilience were associated with less depression ${ }^{4,7,29}$ and better physical health. ${ }^{2,3}$ Other biological factors associated with higher levels of resilience were: older age, ${ }^{14}$ African-American ethnicity ${ }^{29}$ and female sex. ${ }^{28}$

\section{Resilience and social factors $(n=5)$}

Studies found a positive association between higher levels of resilience and social factors, such as good social support, 2,15,20 satisfaction with social support ${ }^{20}$ and individual, family, and community resources. ${ }^{19}$

\section{Methods}

Most studies were cross-sectional, ${ }^{1-3,5,6,10,12-14,18,24}$ but longitudinal $\left.\right|^{4,28,29}$ and descriptive ${ }^{1,3,5,10,14,24}$ designs were also used.

Most samples included caregivers of people with Alzheimer's disease (AD). 1,3,4,7,12,14,18,29 Caregivers of people with $A D$ and vascular dementia (VD) were included in one study, ${ }^{10}$ and caregivers of people with $A D, V D$ and mixed dementia (MD) were compared in $13 \%$ of the studies. ${ }^{2,6}$ Two studies compared $A D$ and similar disorders, ${ }^{13,28}$ and two did not specify the type of dementia under study. 5,24

The most frequent assessment instrument was the complete and brief versions of the Resilience Scale developed by Wagnild \& Young. ${ }^{3,5,12,13,18}$ Other instruments were the Connor-Davidson Resilience Scale $(C D-R I S C)^{2,7}$ and the Dispositional Resilience Scale. ${ }^{4}$ Two studies did not have any specific instrument to assess resilience, but used scales that assess associated constructs, such as the Resourcefulness Scale $^{1}$ and the Battery of Generalized Expectancies of Control Scales (BEEGC-20). ${ }^{6}$ One study ${ }^{28}$ administered the Zarit Burden Interview to assess resilience and analyzed results according to reports of burden and frequency of demands of the person with dementia. In one study ${ }^{29}$ the Center for Epidemiological Studies Depression Scale (CES-D), Life Satisfaction Index (LSI-Z) and the brief and revised version of the Social Support Questionnaire (SSQSR) were used. Finally, two studies used qualitative interviews that were fully transcribed and analyzed. ${ }^{10,24}$

The determinant factors and the methods of studies about resilience are shown in Table 2 .

\section{Discussion}

\section{Resilience definition}

We conducted a search to retrieve studies that discussed the definitions and determinants of resilience among caregivers of people with dementia. We did not find a consensus about how to define resilience, as several terms are used as synonyms for it: adaptation when faced with adversity; ${ }^{1,2,4,5,13,14,18}$ flexibility ${ }^{13}$; belief in oneself and internal locus of control ${ }^{6}$; efficacious coping ${ }^{2,18}$; psychological well-being and strength ${ }^{12}$; development of a healthy life $^{3}$; perceived burden ${ }^{28}$; and amount of and satisfaction with social support. ${ }^{29}$ Therefore, we concluded that each study defined resilience according to its objectives and assessment methods, rather than based on any clearly established theoretical framework of resilience in dementia. These various definitions may explain the differences found in the results of the studies under assessment here.

The lack of a theoretical framework may give rise to several methodological problems, such as the absence of standardized assessment instruments ${ }^{1,4,6,7,14,28}$ and the heterogeneity of samples. ${ }^{6,12,13,28}$ However, most studies converged on the definition of resilience as the capacity to adapt successfully when faced with the stress of adversity. ${ }^{1,2,4-6,13,14,18}$ Therefore, resilience seems to have some degree of conceptual overlap with similar constructs used in dementia caregiving, such as mastery or degree to which individuals attribute outcomes to their own efforts or abilities, self-efficacy, internal locus of control, and learned helplessness. Other constructs, possibly shared by resilience, are personality traits, such as neuroticism, which may predispose some caregivers of people with dementia to reporting greater feelings of burden, behavior problems or subjective ratings of health. Therefore, it remains unclear whether resilience is a learning ability or a personality trait. 


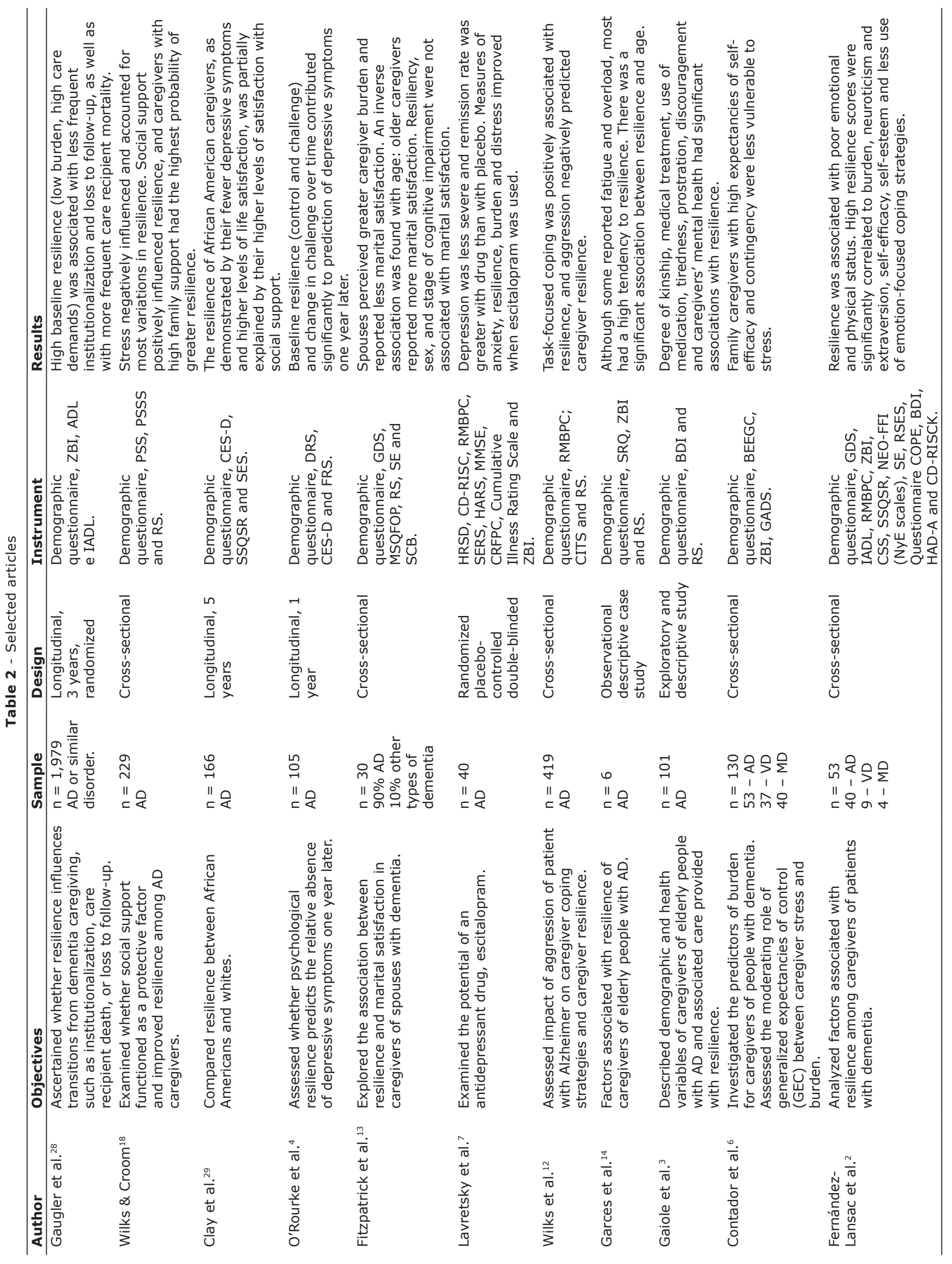




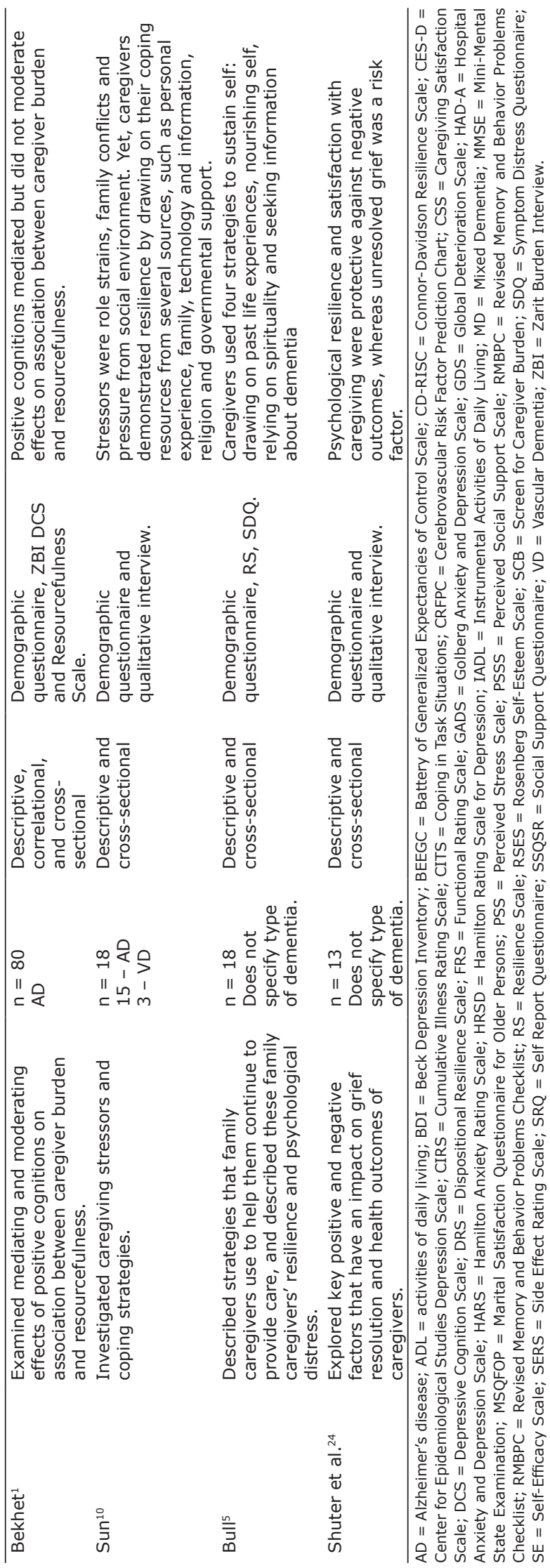

Resilience should be understood not only as a personal attribute that may lead to success, but also as the dynamic interaction between biological and psychosocial processes. Resilience of caregivers of people with dementia should be defined in association with caregiving tasks, because it implies resistance to stress due to the perception of caregiving demands and burden. This definition suggests that resilience should be assessed in association with reports of burden and frequency of demands from care recipients, which may be associated with neuropsychiatric symptoms and functional dependence. ${ }^{28}$

\section{Psychological factors}

In general, higher control over life helps adaptation and improves understanding of the situation, acceptance of changes and confidence of caregivers on their own strength and on the affective bonds shared with care recipients. ${ }^{2}$ Therefore, resilience may be understood as a force, a strategy and a set of skills used in a specific context by a particular individual to deal with a particular adverse event. The coping strategy adopted by caregivers with greater resilience is task focused. ${ }^{10,12}$ This strong association between task-focused coping and resilience suggests that task-focused skills training programs may improve and protect caregiver mental health and prolong the time a loved one may remain at home. ${ }^{12}$

According to Contador et al., ${ }^{6}$ optimistic people make a subjective estimate of the probability of achieving goals or desired results based on other factors, such as self-efficacy (belief in their own capacity of starting actions, achieving goals and dealing with life) and internal locus of control or contingency (how individuals expect life events or results to be motivated by their actions). Self-efficacy and internal locus of control are psychological factors that support the construct of resilience and are associated with less suffering from the negative effects of stress and burden. Therefore, people with grounded optimism, high level of self-efficacy and internal locus of control may be more resilient to stressful situations, which may reduce vulnerability to burden. ${ }^{6}$

O'Rourke et al. $^{4}$ assessed three constructs that compose resilience. The first was commitment to life, as resilient people tend to engage fully in daily activities. Second, resilient people enjoy challenges and prefer changes rather than stability, and life travails provide opportunities to develop skills and self-knowledge. ${ }^{4}$ Finally, psychological resilience entails perceived control, which results in a sense of personal autonomy and a belief in being able to directly affect the course of life events. ${ }^{4}$ 
These characteristics, associated with burden, stress and distress, may be protective factors or risk factors for people with dementia. Some authors suggest that higher levels of resilience are inversely associated with low burden, ${ }^{1,2,28}$ stress $^{6}$ and distress levels. ${ }^{5,24}$

Bekhet ${ }^{1}$ concluded that positive cognitions are protective factors for caregivers of people with dementia. Positive cognitions, or positive thinking patterns, enhance mental health and improve the capacity to manage daily activities. ${ }^{1}$

\section{Biological factors}

Higher resilience scores were associated with improved physical health. ${ }^{2}$ Caregivers with lower resilience scores tended to visit the doctor less frequently and take less medicine. This might be related to a lower degree of selfcare. Comparatively, higher degrees of resilience were associated to fewer alterations of health habits ${ }^{2}$ and better physical health. ${ }^{3}$ Moreover, higher degrees of resilience were associated to low somatization and depression. ${ }^{3}$

The role of mood in resilience was demonstrated by Lavretsky et al., ${ }^{7}$ who concluded that antidepressant use in depressed family dementia caregivers with either major or minor depression might improve depression symptoms, boost resistance to stress and improve coping strategies. Moreover, there is a significant association between resilience and aging, which indicates that resilience is acquired as the person gets older. ${ }^{14}$ This finding is important because caregivers are the same age as elderly people with dementia. Further studies should investigate the neurophysiologic mechanisms of resilience and their association with psychological functioning and social factors.

\section{Social factors}

Social support has been positively associated with resilience, ${ }^{2,18,29}$ but studies have defined support in different ways: network size and frequency of contact; support received; frequency of help from other people; and general satisfaction with social network. ${ }^{29}$ Social support associated with perceived help and satisfaction with support seem to be more consistent than actual support or size of support network. ${ }^{29}$ A study ${ }^{29}$ that assessed ethnic differences in resilience found that resilience of Afro-American caregivers was partially explained by higher levels of satisfaction with social support.

Wilks \& Croom $^{18}$ found an inverse association of social support and stress resulting from the combination of: a) negative influence of stress on caregivers' perception about available social resources; b) negative influence of stress on caregivers' capacity of using these resources; and c) higher perception of available social resources associated with lower probability of perceived stress.
Therefore, social support is a moderating factor of resilience, as several types of support may relatively relieve the physical and mental burden caused by stress. ${ }^{18}$

Therefore, resilience is a dynamic process believed to arise from interactions between biological and psychosocial factors. This process involves physiological adaptation to stress, psychological adjustment, selfefficacy, effective coping strategies and cognitive redefinition of experience. However, studies in the area often focus on only one factor, such as coping. 1,3,6,7,12-14,18 Clinically, partial assessments of resilience may compromise the development of interventions focused on the improvement of this capacity among caregivers of people with dementia.

\section{Methods and instruments: difficulties in the assessment of resilience}

Although the assessment of dynamic constructs, such as resilience, may be methodologically limited, most studies in this review were cross-sectional. $1,2,5,6,10,12,13,18,24$ Longitudinal studies would be more appropriate because they would follow the development of resilience among caregivers and the cognitive decline of people with dementia, as well as the increase of care demands.

Most samples included caregivers of people with $A D, 1,3,4,7,12,14,18,29$ but some assessed, without comparing, caregivers of people with $A D, V D, M D$, mild cognitive impairment (MCI) or unspecified dementia. ${ }^{2,6,10,13,28}$ There are important clinical differences between types of dementia and, therefore, between different forms of caring. Heterogeneous samples, found in some studies, precluded the assessment of some factors, such as resilience.

In all studies, most participants were informal female caregivers ${ }^{1-7,10,12-14,18,24,28,29}$ and spouses or children of elderly people with dementia, ${ }^{1-6,10,12-14,18,24}$ whose mean age was 60 years ${ }^{2-5,7,10,13,14,24,28,29}$ and whose mean schooling was eight years. ${ }^{1,2,3,5-7,13,14}$ This caregiver profile indicates that elderly people have been taking care of elderly people, and the most important challenge is to prevent and treat the diseases that may affect caregivers. The study of resilience may bring results that define a protective factor for caregivers.

The use of assessment instruments that provide only partial data might have limited the understanding of resilience. The instrument most often used to assess resilience was the complete or brief version of the Resilience Scale of Wagnild \& Young. ${ }^{3,5,12-14,18}$ This scale measures factors associated with resilience, such as selfesteem, locus of control, coping styles and sense of humor. However, the lack of a consensus about the definition of constructs resulted on the use of different instruments, including those designed to assess depression and 
burden, which makes it difficult to replicate these studies and raises questions about the reliability of their results.

\section{Conclusion}

Resilience is a process associated with adaptive capacities and a positive history of functioning and adaptation after adversities. This dynamic process involves the interaction between biological and psychosocial factors, which makes its investigation more complex. As studies define resilience differently, consistent results are difficult to obtain, which affects the understanding and the investigation of associated factors.

Clinically, knowledge about factors associated with resilience may lead to the development of psychological and educational support for caregivers of people with dementia. Support groups should be focused not only on information and feelings about the diagnosis and caregiving routines, but also on the factors that may increase resilience among caregivers, such as task-focused coping strategies and self-efficacy. However, future, welldesigned studies should use a clear definition of resilience and adequate instruments to measure it, have coherent objectives and include randomized samples.

Longitudinal studies should be conducted to follow disease progression, examine associations with other variables and understand the dynamics of resilience, which may positively affect the quality of life of caregivers of people with dementia.

\section{Acknowledgements}

Fundação de Amparo à Pesquisa do Estado do Rio de Janeiro (FAPERJ; grant no. E-26/102.256/2010) financed the expenses with the development of this study.

\section{References}

1. Bekhet AK. Effects of positive cognitions and resourcefulness on caregiver burden among caregivers of persons with dementia. Int J Ment Health Nurs. 2013;22:340-6. Epub 2012 Sep 25.

2. Fernández-Lansac V, Crespo López M, Cáceres R, RodríguezPoyo M. [Resilience in caregivers of patients with dementia: A preliminary study]. Rev Esp Geriatr Gerontol. 2012;47:102-9. Epub 2012 May 11.

3. Gaiole CC, Furegato AR, Santos JL. Perfil de cuidadores de idosos com doença de Alzheimer associado à resiliência. Texto Contexto Enferm. 2012;21:150-7.

4. O'Rourke N, Kupferschmidt AL, Claxton A, Smith JZ, Chappell N, Beattie BL. Psychological resilience predicts depressive symptoms among spouses of persons with Alzheimer disease over time. Aging Ment Health. 2010;14:984-93.

5. Bull MJ. Strategies for sustaining self used by family caregivers for older adults with dementia. J Holist Nurs. 2014;32:127-35. Epub 2013 Nov 13.

6. Contador I, Fernández-Calvo B, Palenzuela DL, Miguéis S,
Ramos F. Prediction of burden in family caregivers of patients with dementia: a perspective of optimism based on generalized expectancies of control. Aging Ment Health. 2012;16:675-82.

7. Lavretsky $H$, Siddarth $P$, Irwin MR. Improving depression and enhancing resilience in family dementia caregivers: a pilot randomized placebo-controlled trial of escitalopram. Am J Geriatr Psychiatry. 2010;18:154-62.

8. Matsushita M, Ishikawa T, Koyama A, Hasegawa N, Ichimi N, Yano $\mathrm{H}$, et al. Is sense of coherence helpful in coping with caregiver burden for dementia? Psychogeriatrics. 2014;14:87-92.

9. Santos RL, de Sousa MF, Arcoverde C, Dourado MC. Eficácia de um grupo psicoeducacional com cuidadores de pessoas com demência. Rev Psiquiatr Clin 2013;40:162-4.

10. Sun F. Caregiving stress and coping: A thematic analysis of Chinese family caregivers of persons with dementia. Dementia (London). 2014;13:803-18.

11. Truzzi A, Valente L, Ulstein I, Engelhardt E, Laks J, Engedal K. Burnout in familial caregivers of patients with dementia. Rev Bras Psiquiatr. 2012;34:405-12.

12. Wilks SE, Little KG, Gough HR, Spurlock WJ. Alzheimer's aggression: influences on caregiver coping and resilience. J Gerontol Soc Work. 2011;54:260-75.

13. Fitzpatrick $K E$, Vacha-Haase $T$. Marital satisfaction and resilience in caregivers of spouses with dementia. Clin Gerontol. 2010;33:165-80.

14. Garces SB, Krug MR, Hansen D, Brunelli AV, da Costa FT, Rosa $C B$, et al. Avaliação da resiliência do cuidador de idosos com Alzheimer. Rev Bras Geriatr Gerontol. 2012;15:335-52.

15. Brandão JM, Mahfoud M, Gianordoli-Nascimento IF. A construção do conceito de resiliência em psicologia: discutindo origens. Paideia. 2011;21:263-71.

16. Yunes MA. Psicologia positiva e resiliência: o foco no indivíduo e na família. Psicol Estud. 2003;08:75-84.

17. Norris FH, Stevens SP, Pfefferbaum B, Wyche KF, Pfefferbaum RL. Community resilience as a metaphor, theory, set of capacities, and strategy for disaster readiness. Am J Community Psychol. 2008; 41:127-50.

18. Wilks SE, Croom B. Perceived stress and resilience in Alzheimer's disease caregivers: testing moderation and mediation models of social support. Aging Ment Health. 2008;12:357-65.

19. Cowan PA, Cowan $C P$, Schulz MS. Thinking about risk and resilience in families. In: Hethering EM, Blecheman EA, editors. Stress, coping and resilience in children and families. New Jersey: Lawrence Erlbaum; 1996. p. 1-38.

20. Reppold CT, Mayer JC, Almeida LS, Hutz CS. Avaliação da resiliência: controvérsia em torno do uso das escalas. Psicol Refl Crit. 2012;25:248-55.

21. Trombeta LH, Guzzo RS. Enfrentando o cotidiano adverso: estudo sobre resiliência em adolescentes. Campinas: Alínea; 2002.

22. Garity J. Caring for a family member with Alzheimer's disease: coping with caregiver burden post-nursing home placement. J Gerontol Nurs. 2006:32:39-48.

23. Hodge DR, Sun F. Positive feelings of caregiving among Latino Alzheimer's family caregivers: understanding the role of spirituality. Aging Ment Health. 2012;16:689-98.

24. Shuter $P$, Beattie E, Edwards $H$. An exploratory study of grief and health-related quality of life for caregivers of people with dementia. Am J Alzheimers Dis Other Demen. 2013;29:379-85.

25. Antonovsky A. Unraveling the mystery of health: how people manage stress ans stay well. São Francisco: Jossey-Bass; 1987

26. Pesce RP, Assis SG, Avanci JQ, Santos NC, Malaquias JV, Carvalhaes R. Adaptação transcultural, confiabilidade e validade da escala de resiliência. Cad Saude Publica. 2005;21:436-48.

27. Higgins JP, Green S. Cochrane Handbook for Systematic Reviews of Interventions Version 5.1.0 [updated March 2011]. The Cochrane Collaboration, 2011. www.cochrane-handbook.org.

28. Gaugler JE, Kane RL, Newcomer R. Resilience and transitions from dementia caregiving. J Gerontol B Psychol Sci Sco Sci. 2007;62:P38-44.

29. Clay OJ, Roth DL, Wadley VG, Haley WE. Changes in social support and their impact on psychosocial outcome over a 5-year period for African American and White dementia caregivers. Int J Geriatr Psychiatry. 2008;23:857-62.

\section{Correspondence:}

Rachel Dias

Rua Carolina Alves, 07

24322-310 - Niterói, RJ - Brazil

Tel. : +55 (21) 99876-1145

E-mail: diasrachel@gmail.com 